\title{
Sodium nitrite and ascorbic acid: a metal-free combination that controls the free-radical polymerization of tert-butyl methacrylate in water
}

\author{
Christophe Detrembleur ${ }^{1 \#}$, Ange Mouithys-Mickalad ${ }^{2}$, Philippe Teyssié ${ }^{1}$, \\ Robert Jérôme ${ }^{1 *}$
}

${ }^{1}$ Center for Education and Research on Macromolecules (CERM), University of Liège, Sart-Tilman, B6, 4000 Liège, Belgium; Fax (32)4-3663497; rjerome@ulg.ac.be

${ }^{2}$ Center for Oxygen R\&D (CORD), University of Liège, Sart-Tilman, B6, 4000 Liège, Belgium; Fax (32)4-3662866; amouithys@ulg.ac.be

(Received: October 26, 2001; published: February 18, 2002)

\begin{abstract}
A mixture of sodium nitrite and ascorbic acid is able to control the radical polymerization of tert-butyl methacrylate (tBMA) in water at $80^{\circ} \mathrm{C}$. Indeed, sodium nitrite is reduced by the ascorbic acid, and the nitric oxide (NO) which is formed in situ is nothing but a promoter of nitroxyl radicals. The radical polymerization of tBMA is thus basically controlled by a nitroxide-mediated process.
\end{abstract}

\section{Introduction}

Controlled radical polymerization (CRP) has expanded very rapidly for the last few years as results of major advances in nitroxide-mediated polymerization (NMP) [1], atom transfer radical polymerization (ATRP) [2] and reversible addition-fragmentation chain transfer (RAFT) [3]. The high efficiency of these CRP systems allows to prepare well-defined (co)polymers (controlled molecular weight, polydispersity, chainends and molecular architecture) with specific properties and potential applications (thermoplastic elastomers, adhesives, dispersants ...). Moreover, the application field of CRP was successfully extended to water-borne systems [4]. Although the three main CRP methods (NMP, ATRP, RAFT) have a similar scope, they may differ in their balance of advantages and limitations. At the time being, none of the CRP techniques is able to control the polymerization of all monomers polymerizable by a free radical mechanism.

In a previous paper, we reported on the controlled radical polymerization of tert-butyl methacrylate in the presence of sodium nitrite and iron(II) sulfate in water at $80^{\circ} \mathrm{C}$ [5]. Consistently with the scientific literature and experiments carried out in that work, a four-step mechanism was proposed for the control observed, viz.,

- formation of nitric oxide by reduction of $\mathrm{NaNO}_{2}$ by $\mathrm{FeSO}_{4}$;

- reaction of the propagating radicals with $\mathrm{NO}$ and formation of nitroso compounds;

- further reaction of the propagating radicals with the nitroso compounds and formation of the parent nitroxyl radicals;

\footnotetext{
\# Present address: Bayer AG, Leverkusen, Germany.
} 
- reversible trapping of the growing chains by the nitroxyl radicals, which leads to a dynamic equilibrium between active and dormant species, at the origin of the polymerization control.

The addition of $\mathrm{FeSO}_{4}$ to sodium nitrite was necessary to impart control to the radical polymerization, in contrast to Bortel et al. who reported on the radical polymerization of acrylic acid in the presence of sodium nitrite only [6]. Polydispersity $\left(M_{w} / M_{n}\right)$ of the poly(acrylic acid) was however very large $(\geq 6)$, in line with a poor control of the reaction.

Although the sodium nitrite/ $\mathrm{FeSO}_{4}$ system allows to control the polymerization of tBMA in water under mild conditions, the final polymer is contaminated by metallic residues which might be an unacceptable drawback. Therefore, the search for an inorganic compound that could activate the release of $\mathrm{NO}$ from $\mathrm{NaNO}_{2}$ is a valuable target. This paper aims at reporting on the beneficial effect of ascorbic acid, which reacts rapidly with sodium nitrite and quantitatively forms nitric oxide (NO) [7]. Radical polymerization of tBMA has thus been studied in water in the presence of a mixture of $\mathrm{NaNO}_{2}$ and ascorbic acid instead of $\mathrm{FeSO}_{4}$.

\section{Experimental part}

\section{Materials}

tert-Butyl methacrylate (tBMA) from BASF was distilled just before use in order to remove the stabilizer. Bidistilled water and acetonitrile were degassed prior to use. $\mathrm{K}_{2} \mathrm{~S}_{2} \mathrm{O}_{8}, \mathrm{FeSO}_{4} \cdot 7 \mathrm{H}_{2} \mathrm{O}$, a, a'-azoisobutyronitrile (AIBN), L(+)-ascorbic acid and $\mathrm{NaNO}_{2}$ were used as received. Liquids were transferred under nitrogen by syringes or stainless steel capillaries.

\section{Polymerization}

$\mathrm{NaNO}_{2} /$ ascorbic acid/ $\mathrm{K}_{2} \mathrm{~S}_{2} \mathrm{O}_{8}$ (or AIBN) ternary system

In a typical procedure, a known amount of $\mathrm{NaNO}_{2}$ was added into the reaction flask that was evacuated by three nitrogen-vacuum cycles. Degassed water and tBMA were then added, and the flask was thermostated at $80^{\circ} \mathrm{C}$. The degassed solution of ascorbic acid in water was added to the flask followed by the aqueous solution of $\mathrm{K}_{2} \mathrm{~S}_{2} \mathrm{O}_{8}$ or the solution of AIBN in acetonitrile. Samples were regularly withdrawn from the polymerization medium, and the monomer conversion was calculated by ${ }^{1} \mathrm{H}$ NMR analysis of the organic phase. Polymerization was stopped after $24 \mathrm{~h}$ because the high viscosity of the medium prevented additional samples from being withdrawn.

\section{Monomer resumption. Synthesis of the poly(tBMA) macroinitiator}

$0.1656 \mathrm{~g} \mathrm{NaNO}_{2}\left(2.4 \cdot 10^{-3} \mathrm{~mol}\right)$ was added into the reaction flask that was evacuated by three nitrogen-vacuum cycles. $40 \mathrm{ml}$ of degassed water and $32 \mathrm{ml}$ of tBMA were then added, and the flask was thermostated at $80^{\circ} \mathrm{C} .20 \mathrm{ml}$ of degassed solution of ascorbic acid (0.8452 $\mathrm{g}$ of ascorbic acid in $40 \mathrm{ml}$ water) was added to the flask, followed by $20 \mathrm{ml}$ of the degassed solution of $\mathrm{K}_{2} \mathrm{~S}_{2} \mathrm{O}_{8}\left(0.811 \mathrm{~g}\right.$ of $\mathrm{K}_{2} \mathrm{~S}_{2} \mathrm{O}_{8}$ in $50 \mathrm{ml}$ of water). After $1 \mathrm{~h}$ of reaction, water and residual monomer were eliminated in vacuum and the residue was dried at room temperature overnight. Conversion $\approx 10 \%$. 


\section{Resumption experiment}

$10 \mathrm{ml}$ of tBMA were added to the degassed crude macroinitiator and the flask was heated at $80^{\circ} \mathrm{C}$ in an oil bath. Samples were regularly withdrawn from the polymerization medium and the monomer conversion was calculated gravimetrically after drying in vacuum at $80^{\circ} \mathrm{C}$, taking into account the amount of non-volatile residue.

\section{Characterization}

Size exclusion chromatography (SEC) was carried out in tetrahydrofuran (THF) at $40^{\circ} \mathrm{C}$ using a Hewlett-Packard 1090 liquid chromatograph equipped with a HewlettPackard 1037A refractive index detector (columns HP PL gel $5 \mu\left(10^{5} \AA, 10^{4} \AA, 10^{3} \AA\right.$, $100 \AA)$ ) and a Waters 600 liquid chromatograph equipped with a 410 refractive index detector (columns Styragel HR (HR1: 100-5000; HR2: 500-20000; HR4: 5000$600000)$ ). The columns were calibrated with poly(methyl methacrylate) (PMMA) standards. Electron spin resonance (ESR) spectra were recorded with a Bruker ESP$300 \mathrm{E}$ ESR spectrometer (equipped with a variable temperature controller accessory) at a frequency of $9.45 \mathrm{GHz}$, a microwave power of $20 \mathrm{~mW}$ and a modulation amplitude of $1 \mathrm{G} .0 .5 \mathrm{ml}$ of the solution to be analyzed was introduced into an EPR tube (o.d. $4 \mathrm{~mm}$ ) that was closed with a rubber septum. This solution was degassed by three freeze-pump-thaw cycles. Spectra were recorded at the desired temperature.

\section{Results and discussion}

Fig. 1 shows the dependence of $M_{n}$ on the tBMA conversion for polymerization initiated by potassium peroxodisulfate in the presence of a $1 / 1(\mathrm{~mol} / \mathrm{mol})$ sodium nitrite/ascorbic acid mixture, in water at $80^{\circ} \mathrm{C}$. A linear evolution of $M_{n}$ is observed until $45 \%$ conversion ( $24 \mathrm{~h}$ of polymerization).

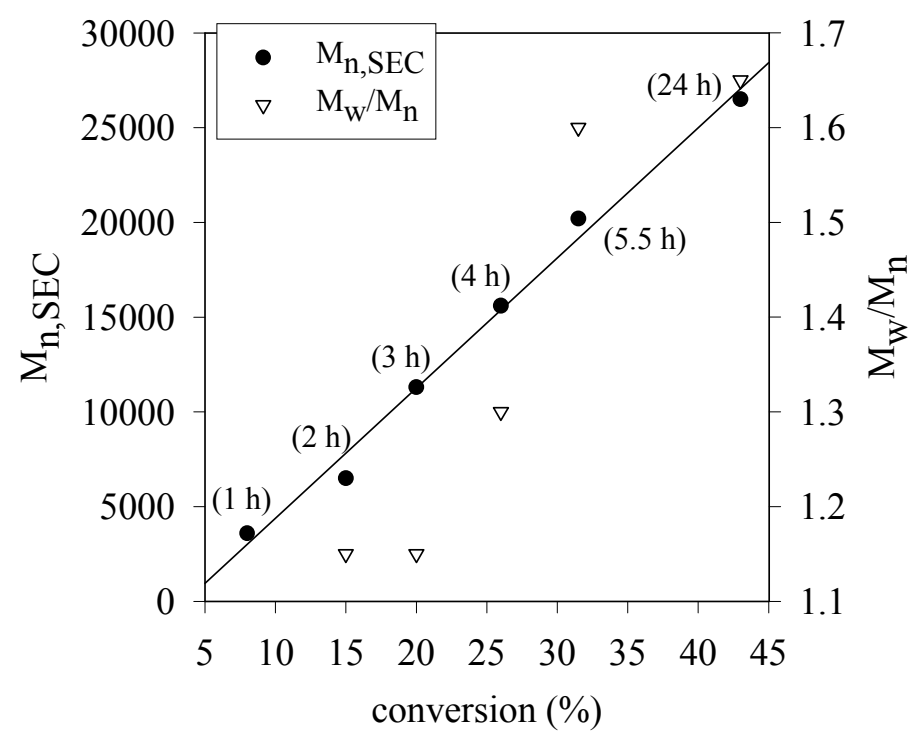

Fig. 1. Dependence of $M_{n}$ on conversion for the tBMA polymerization initiated by $\mathrm{K}_{2} \mathrm{~S}_{2} \mathrm{O}_{8}$ in the presence of sodium nitrite and ascorbic acid, in water at $80^{\circ} \mathrm{C}$. (2 eq. $\mathrm{NaNO}_{2}, 2$ eq. ascorbic acid, 1 eq. $\mathrm{K}_{2} \mathrm{~S}_{2} \mathrm{O}_{8}, 168$ eq. tBMA, water/tBMA = 2.5.) Ratios in figure captions are mole ratios if not given otherwise 
Because tBMA is not miscible with water, droplets of the organic phase (tBMA, growing polymer chains) are mechanically dispersed in the aqueous phase, and no precipitation of PtBMA is observed during polymerization. No additional sample could be picked out for analysis after $24 \mathrm{~h}$ of reaction because of the high viscosity of the polymerization medium.

Although the polydispersity is low at the early stage of the polymerization $\left(M_{w} / M_{n} \leq\right.$ 1.1, Fig. 1), it becomes larger during polymerization, although the molecular weight distribution remains monomodal all along the polymerization. Additionally, a decrease in the polymerization rate is observed after $4 \mathrm{~h}$ of reaction (31\% of monomer conversion after $4 \mathrm{~h}$ compared to $43 \%$ after $24 \mathrm{~h}$ ). This observation might suggest that either side reaction occurs or the equilibrium between dormant and active chains is shifted toward the dormant chains as result of the continuous formation of active species in the medium.

\section{Influence of the amount of ascorbic acid}

When the amount of ascorbic acid is decreased at constant amount of the other constituents (sodium nitrite/ascorbic acid mole ratio $=1.0 / 0.25$ ), a linear dependence of $\mathrm{M}_{\mathrm{n}}$ on the monomer conversion is observed until high monomer conversion (78\% after $24 \mathrm{~h}$ ). Moreover, an increase in the sodium nitrite/ascorbic acid mole ratio from $1 / 1$ to $1.0 / 0.25$ does not affect the molecular weight of the polymer (Fig. 2) and the polydispersity which increases with time $(1.35$ at $15 \%$ of monomer conversion compared to 2.4 at $80 \%$ ).

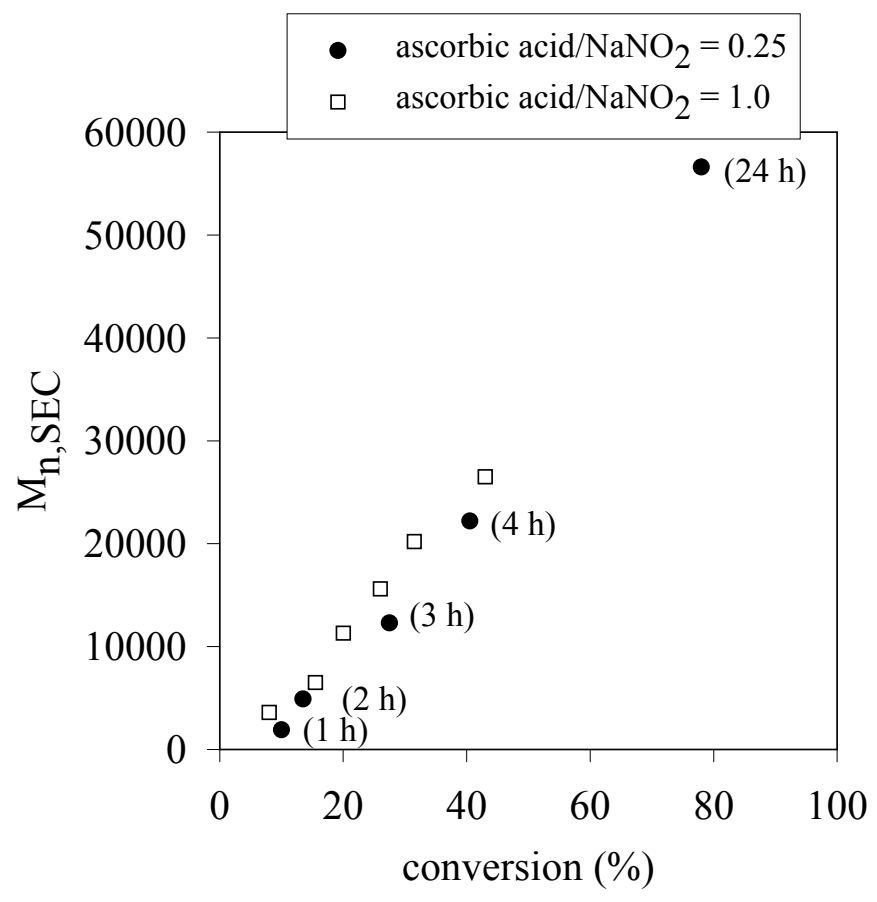

Fig. 2. Dependence of $M_{n}$ on conversion for the tBMA polymerization initiated by $\mathrm{K}_{2} \mathrm{~S}_{2} \mathrm{O}_{8}$ in the presence of sodium nitrite and ascorbic acid, in water at $80^{\circ} \mathrm{C}$. The amount of ascorbic acid was changed in contrast to the amount of the other constituents that remained constant. (2 eq. $\mathrm{NaNO}_{2}, 1$ eq. $\mathrm{K}_{2} \mathrm{~S}_{2} \mathrm{O}_{8}, 168$ eq. tBMA, water/tBMA $=2.5$ ) 
Fig. 3 shows that the molecular weight of poly(tBMA) increases with reaction time and that a tailing on the low-molecular-weight side is responsible for the increasing polydispersity. At ca. $80 \%$ monomer conversion, this tailing is dominant which suggests that side reactions (vide infra) occur all along the polymerization.

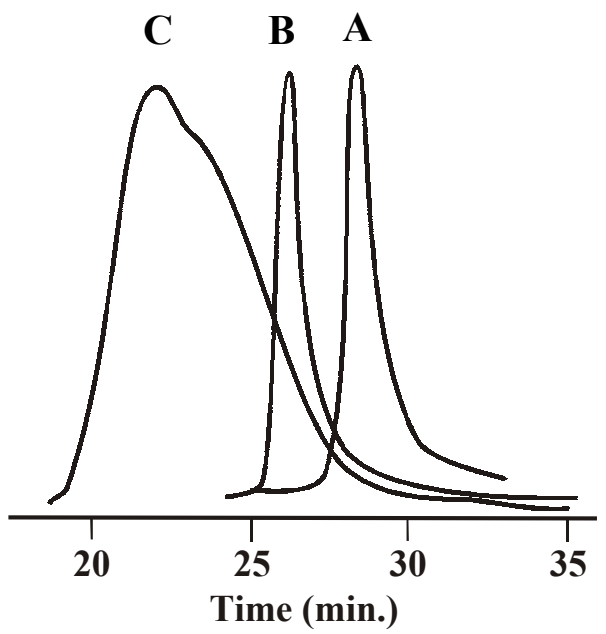

Fig. 3. SEC chromatograms for the tBMA polymerization initiated by $\mathrm{K}_{2} \mathrm{~S}_{2} \mathrm{O}_{8}$ in the presence of sodium nitrite and ascorbic acid (ascorbic acid $/ \mathrm{NaNO}_{2}=0.25$ ), in water at $80^{\circ} \mathrm{C}$ (cf. Fig. 2): (A) 2 h, $M_{n}=4900 ;$ (B) 3 h, $M_{n}=12300 ;$ (C) 24 h, $M_{n}=56600$

Clearly, the addition of the sodium nitrite/ascorbic acid mixture to the tBMA polymerization medium imparts control to the chain growth, although some side reactions occur. It must be noted that the polymerization control does not require large amounts of ascorbic acid, in complete agreement with the experiments in which $\mathrm{FeSO}_{4}$ was used instead of ascorbic acid [5]. Moreover, a low amount of ascorbic acid (or $\mathrm{FeSO}_{4}[5]$ ) is favorable to the polymerization kinetics (Fig. 2). The independence of $\mathrm{Mn}_{n}$ of the amount of ascorbic acid (or $\mathrm{FeSO}_{4}$ [5]) suggests that the initiating radicals basically result from the thermal decomposition of potassium persulfate, and that initiation by the redox reaction of potassium persulfate with ascorbic acid is limited.

It can be concluded that this cheap and metal-free system is able to control the tBMA radical polymerization in water, which is a highly desirable opportunity.

\section{Influence of the initiator}

In addition to the formation of nitric oxide by reaction with sodium nitrite, the ascorbic acid may activate the potassium peroxodisulfate decomposition by an oxydoreduction reaction [8]. In order to prevent the ascorbic acid from reacting with the initiator, potassium peroxodisulfate was replaced by AIBN (Fig. 4). $M_{n}$ increases quasi-linearly with the monomer conversion, and the polydispersity is narrow at the very beginning of the polymerization. Although some side reactions occur with time, the polymerization remains under control. 


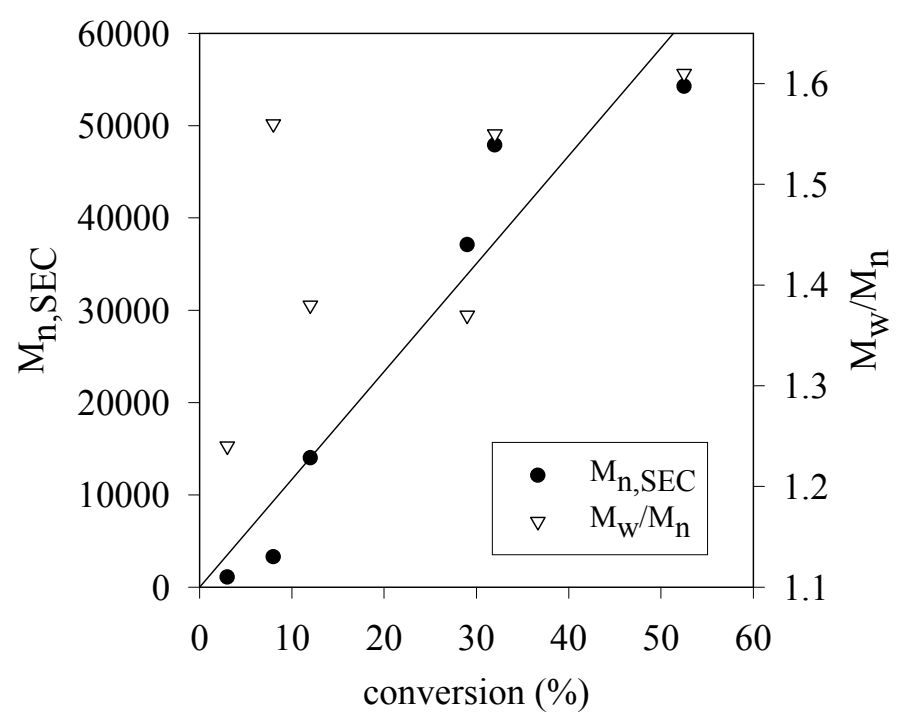

Fig. 4. Dependence of $M_{n}$ and polydispersity on conversion for the tBMA polymerization initiated by AIBN in the presence of sodium nitrite and ascorbic acid, in a $3 / 1(\mathrm{v} / \mathrm{v})$ water/acetonitrile mixture at $80^{\circ} \mathrm{C}$. (4 eq. $\mathrm{NaNO}_{2}, 2$ eq. ascorbic acid, 1 eq. AIBN, 335 eq. tBMA, water/tBMA = 1.25)

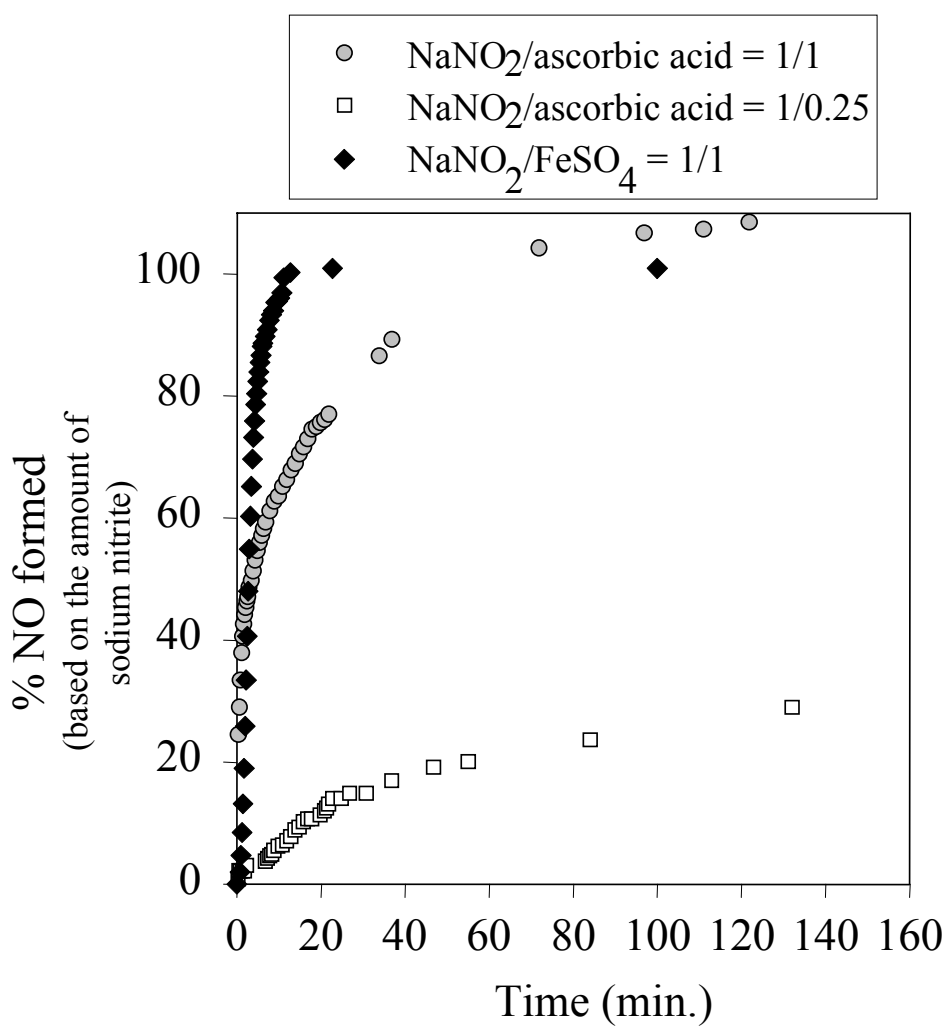

Fig. 5. Volumetric measurement of $\mathrm{NO}$ formation when $\mathrm{NaNO}_{2}$ is reacted with ascorbic acid in water at $80^{\circ} \mathrm{C} .\left(10^{-3} \mathrm{~mol} \mathrm{NaNO}_{2}, 33.5 \mathrm{ml}\right.$ water $)$ 


\section{Polymerization mechanism}

In order to quantify the reaction of ascorbic acid with sodium nitrite, the volume of nitric oxide was measured versus time for two sodium nitrite/ascorbic acid mole ratios (1/1 and 1.0/0.25; Fig. 5) and compared to the sodium nitrite/FeSO 4 (1/1) system. C. $75 \%$ of the theoretical amount of NO is formed after 20 min when the sodium nitrite/ascorbic acid mole ratio is $1 / 1$, and the reaction is complete after $70 \mathrm{~min}$ (experimental error of the volumetric measurement $\approx 5-10 \%$ ). Thus, the reduction of sodium nitrite by ascorbic acid is c. 5 times slower compared to the use of iron (II) sulfate under the same experimental conditions. When the amount of ascorbic acid is four times lower, the amount of $\mathrm{NO}$ is also decreased by a factor of four.

Because ascorbic acid and $\mathrm{FeSO}_{4}$ have quite the same role, i.e. release of nitric oxide from sodium nitrite, the same mechanism as proposed for the $\mathrm{NaNO}_{2} / \mathrm{FeSO}_{4}$ system can be put forward [5]. Scheme 1:

1) Formation of nitric oxide

$$
\mathrm{NaNO}_{2}+\text { ascorbic acid } \longrightarrow \mathrm{NO}
$$

2) Formation of the propagating radicals and nitrosocompounds

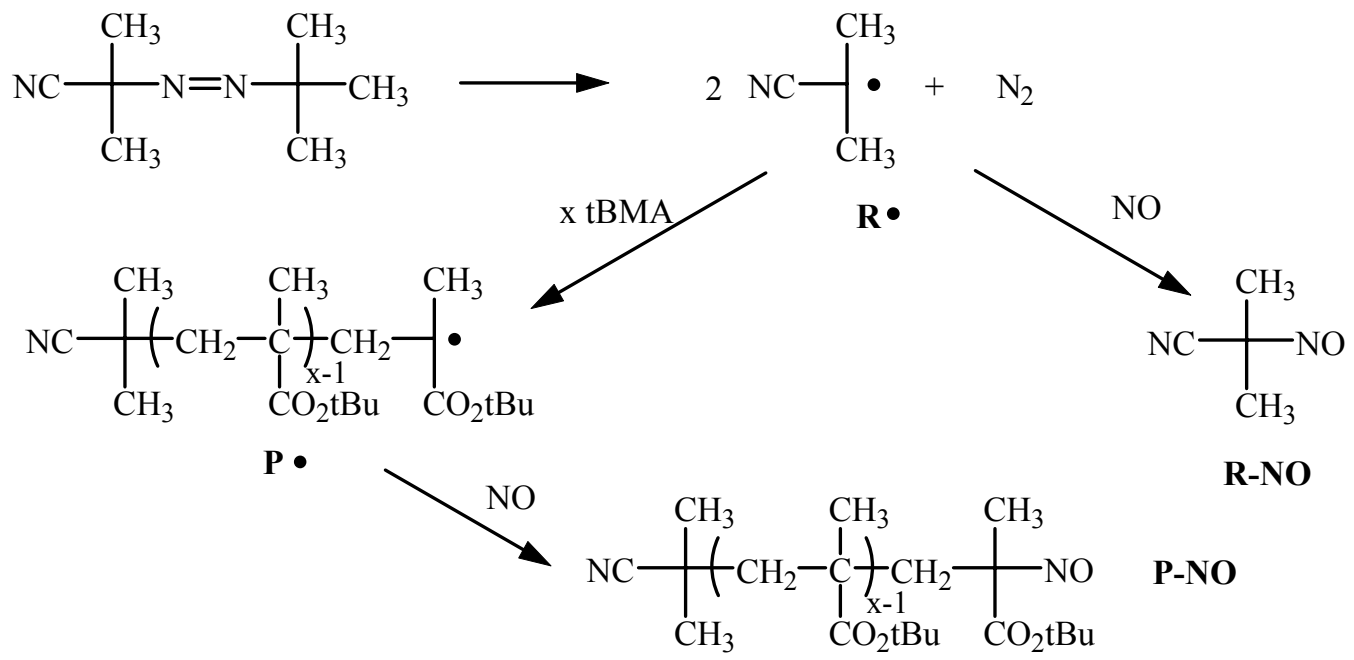

3) Formation of nitroxyl radicals

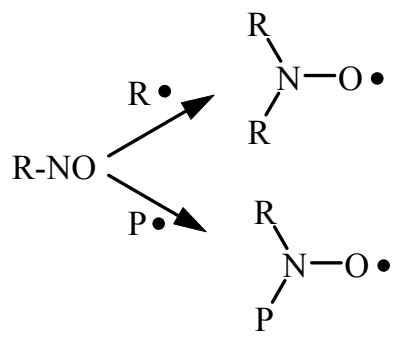

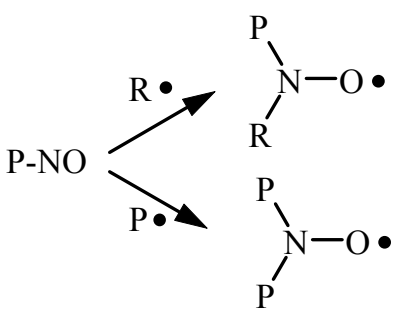

4) Reversible trapping of propagating radicals by nitroxyl radicals

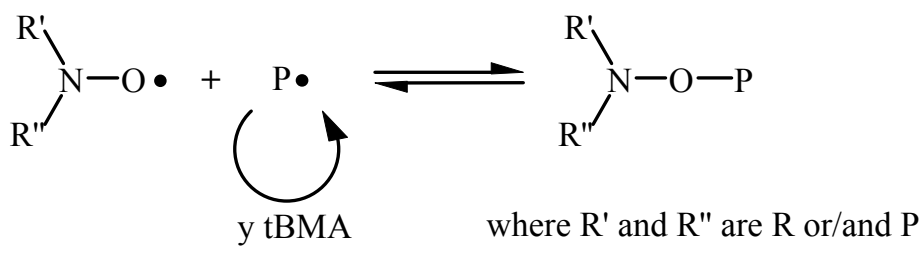


Alkyl radicals add to nitric oxide to form nitroso compounds [9] which are efficient spin-traps [10] for other alkyl radicals with formation of nitroxyl radicals. A nitroxidemediated free-radical polymerization is then operating, based on an equilibrium between propagating chains and dormant chains (i.e., propagating chains trapped by the nitroxyl radicals). The nitroxyl radicals are formed in situ by two successive additions of alkyl radicals to nitric oxide (Scheme 1). This mechanism is in agreement with Grishin et al., who showed that nitroxyl radicals can be formed by reaction of macroradicals with nitroso compounds and control the polymerization of methyl methacrylate in organic medium according to a NMP process [11].

In order to confirm this mechanism, oligomers were synthesized by the sodium nitrite/ ascorbic acid/ $\mathrm{K}_{2} \mathrm{~S}_{2} \mathrm{O}_{8}$ system and analyzed by ESR at $80^{\circ} \mathrm{C}$ (Fig. 6 ).

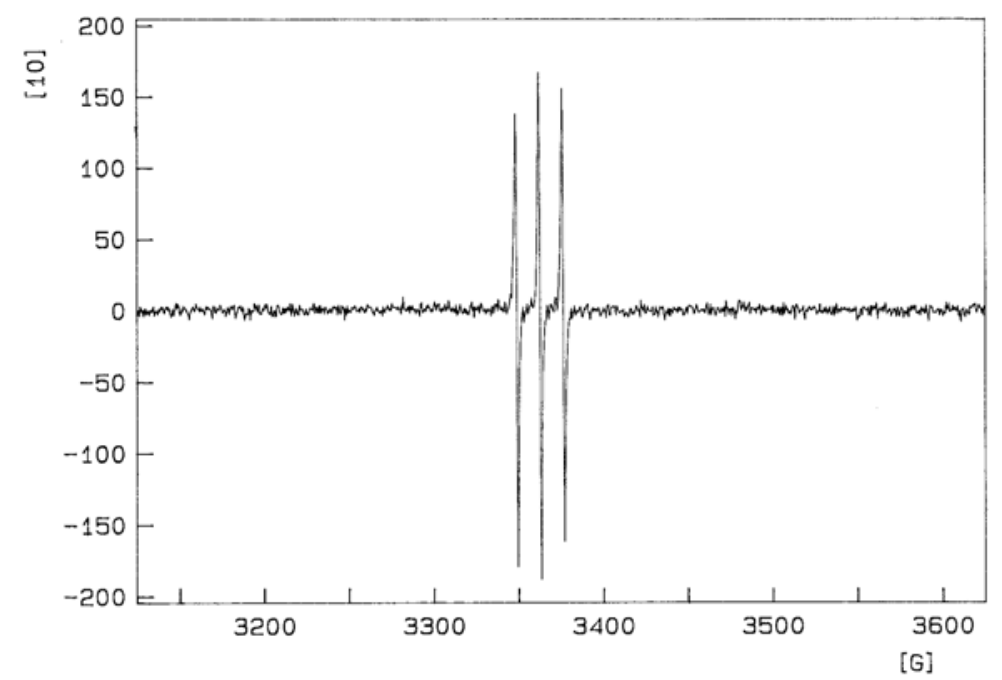

Fig. 6. ESR spectrum, in toluene at $80^{\circ} \mathrm{C}$, for poly(tBMA) formed in water by the $\mathrm{NaNO}_{2} /$ ascorbic acid/ $\mathrm{K}_{2} \mathrm{~S}_{2} \mathrm{O}_{8}$ system. (5mg poly(tBMA) in $0.5 \mathrm{ml}$ toluene)

In case of a NMP mechanism, the oligomers should be end-capped by an alkoxyamine, which upon thermolysis should release a nitroxyl radical detectable by ESR. A three-line ESR spectrum characteristic of nitroxyl radicals, with $A_{N}=13.7 \mathrm{G}$ and a g factor $=2.0078$, is observed and confirms the NMP process. The $A_{N}$ and $g$ values are similar to the ones previously measured in case of the sodium nitrite/iron(II) sulfate/ potassium peroxodisulfate system [5]. They also confirm that the structure of the nitroxyl radicals is similar in the two series of experiments. Additionally, the three-line ESR spectrum results from the hyperfine coupling to nitrogen and is consistent with the bonding of this nitrogen atom to two tertiary carbons. Indeed, in case of bonding of the nitrogen atom to a secondary or primary carbon, a more complex ESR spectrum is observed, as a result of the hyperfine structure resulting from the coupling of free radical and hydrogen atoms linked to these carbons. The ESR spectrum is thus in good agreement with the structure expected for the nitroxyl radical formed in the polymerization medium (see the polymerization mechanism; Scheme 1).

The very weak ESR signal observed at $-83^{\circ} \mathrm{C}$ is more likely due to residual nitroxyl radicals which have not reacted with a macroradical (Fig. 7A). Upon increasing temperature, the ESR signal becomes more intense (Fig. 7), consistently with the release of nitroxyl radicals by thermal rupture of the C-ON bond of the dormant species, as is the case in classical NMP. The lower temperature above which the 
amount of nitroxyl radicals starts to increase (ca. $-70^{\circ} \mathrm{C}$ ) suggests that the $\mathrm{C}-\mathrm{ON}$ bond of the dormant species is very labile, and much more labile than in the TEMPOmediated process $\left(>100^{\circ} \mathrm{C}\right)$. The asymmetric structure of the ESR spectrum at low temperature results from the anisotropy of the system [12].
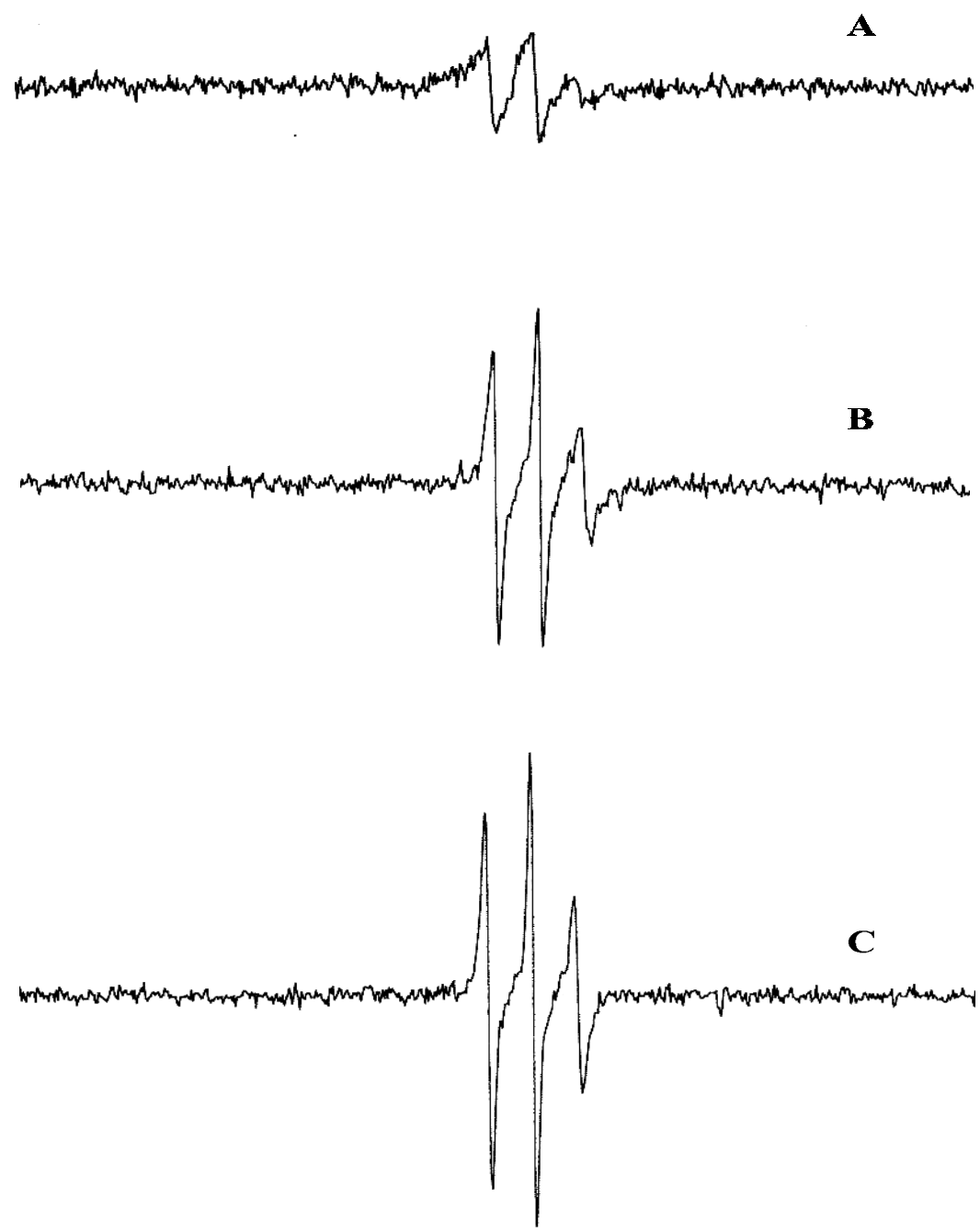

Fig. 7. ESR spectra of poly(tBMA) formed in water by the $\mathrm{NaNO}_{2} /$ ascorbic acid/ $\mathrm{K}_{2} \mathrm{~S}_{2} \mathrm{O}_{8}$ system, in toluene at $-83^{\circ} \mathrm{C}(\mathrm{A}),-53^{\circ} \mathrm{C}(\mathrm{B})$ and $0^{\circ} \mathrm{C}(\mathrm{C})$. (5 mg poly(tBMA) in $0.5 \mathrm{ml}$ toluene)

At $52^{\circ} \mathrm{C}$, a hyperfine structure is observed which is better resolved when the number of scans is increased up to 4 (Fig. 8). This structure might indicate an interaction of the radical with neighboring atoms or formation of other paramagnetic species. Further study is in progress. 


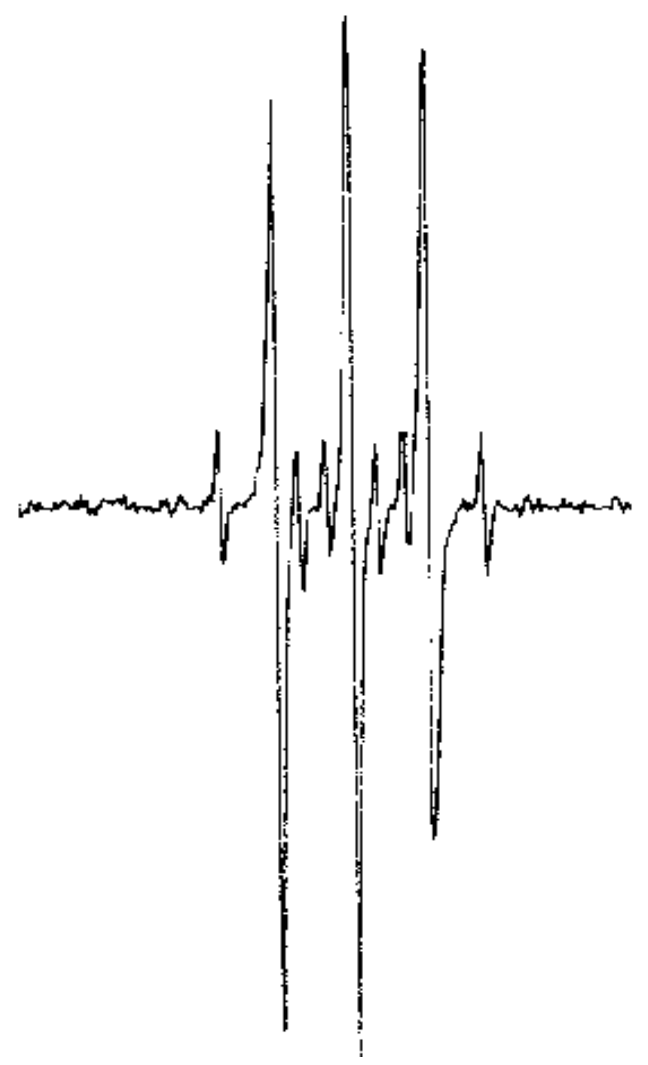

Fig. 8. ESR spectrum, in toluene at $52^{\circ} \mathrm{C}$, for poly(tBMA) formed in water by the $\mathrm{NaNO}_{2}$ /ascorbic acid/ $\mathrm{K}_{2} \mathrm{~S}_{2} \mathrm{O}_{8}$ system. (5 mg poly(tBMA) in $0.5 \mathrm{ml}$ toluene)

When a solution of the oligomers in toluene is heated at $80^{\circ} \mathrm{C}$ for $15 \mathrm{~min}$, the hyperfine structure is no longer observed, and the intensity of the signal is slightly decreased (Fig. 9A). This decrease is however more important when the solution is heated for a longer period of time (Fig. 9B). Thus, at the polymerization temperature of $80^{\circ} \mathrm{C}$, the amount of nitroxyl radicals decreases with time, which is in line with the loss of control observed at increasing monomer conversion. Some side reactions, such as thermal degradation of the nitroxyl radicals or $\beta-\mathrm{H}$ elimination [13] may explain that nitroxyl radicals disappear.

\section{Experiments of monomer resumption}

In order to collect information about the persistency of the species responsible for chain growth, polymerization was resumed by non-purified PtBMA chains synthesized by the $\mathrm{NaNO}_{2}$ /ascorbic acid/ $\mathrm{K}_{2} \mathrm{~S}_{2} \mathrm{O}_{8}$ system. The macroinitiator was not isolated in order to restrict the risks of modification of the chain-end during purification and recovery. Moreover, the PtBMA chains were collected at low monomer conversion (after $1 \mathrm{~h}$ ) because the molecular weight distribution is then narrow. Nevertheless, according to the previous volumetric measurement (Fig. 5), most of the sodium nitrite was decomposed and will not interfere with the resumption experiment. After elimination of water and residual monomer in vacuum, a fresh tBMA feed was added and the medium was heated at $80^{\circ} \mathrm{C}$. 


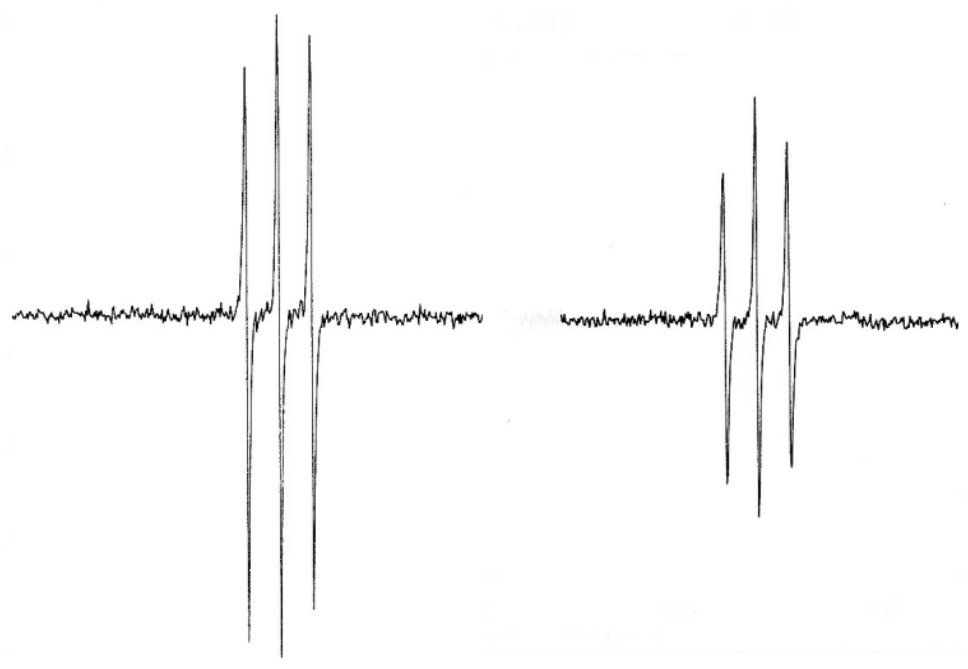

Fig. 9. ESR spectra, in toluene at $80^{\circ} \mathrm{C}$, for poly(tBMA) formed in water by the $\mathrm{NaNO}_{2} /$ ascorbic acid/ $\mathrm{K}_{2} \mathrm{~S}_{2} \mathrm{O}_{8}$ system. After $15 \mathrm{~min}(\mathrm{~A})$ and $1 \mathrm{~h}(\mathrm{~B})$ at $80^{\circ} \mathrm{C}$. (5 mg poly(tBMA) in $0.5 \mathrm{ml}$ toluene)

Fig. 10 shows that $M_{n}$ increases linearly with the monomer conversion until $40 \%$ conversion, in agreement with a controlled process. The molecular weight distribution is narrow during the first hours of polymerization, then it becomes broader with time although it remains monomodal (Fig. 11). Once again, a tailing on the low-molecularweight side is the signature of loss of control. The polymerization rate decreases with increasing monomer conversion $(20 \%$ and $85 \%$ monomer conversions after $2 \mathrm{~h}$ and $48 \mathrm{~h}$, respectively), as previously observed. Beyond $40 \%$ of monomer conversion, the SEC chromatogram is no longer shifted toward higher molecular weight, which suggests that the polymerization is no longer controlled.

It thus appears that the poly(tBMA) chains retain activity after synthesis, even though the control of the resumed polymerization is lost after some time.

The nitrite system: a view on the occurrence of competitive reactions and termination reactions

Although polymerization of tBMA is controlled when initiated by the sodium nitrite system ( $\mathrm{NaNO}_{2} /$ ascorbic acid $/ \mathrm{K}_{2} \mathrm{~S}_{2} \mathrm{O}_{3}$ and $\mathrm{NaNO}_{2} / \mathrm{FeSO}_{4} / \mathrm{K}_{2} \mathrm{~S}_{2} \mathrm{O}_{8}$ [5] systems), competitive reactions occur, which results in a loss of control.

- Sodium nitrite reacts with ascorbic acid (or $\mathrm{FeSO}_{4}$ in the $\mathrm{NaNO}_{2} / \mathrm{FeSO}_{4}$ system) and forms nitric oxide which is the key molecule for the polymerization control. Nevertheless, potassium peroxodisulfate is able to oxidize sodium nitrite into sodium nitrate. This undesirable reaction decreases the amount of sodium nitrite in the polymerization medium and thus the amount of $\mathrm{NO}$ available.

- Moreover, a redox reaction between ascorbic acid (or $\mathrm{FeSO}_{4}$ ) and potassium peroxodisulfate could occur and rapidly form radicals in the medium. The independence of $\mathrm{M}_{n}$ of the amount of ascorbic acid (or $\mathrm{FeSO}_{4}$ [5]), however, suggests that the initiating radicals are basically formed by the thermal decomposition of potassium peroxodisulfate and that initiation by the redox reaction is limited, at least under the conditions used in this work. 


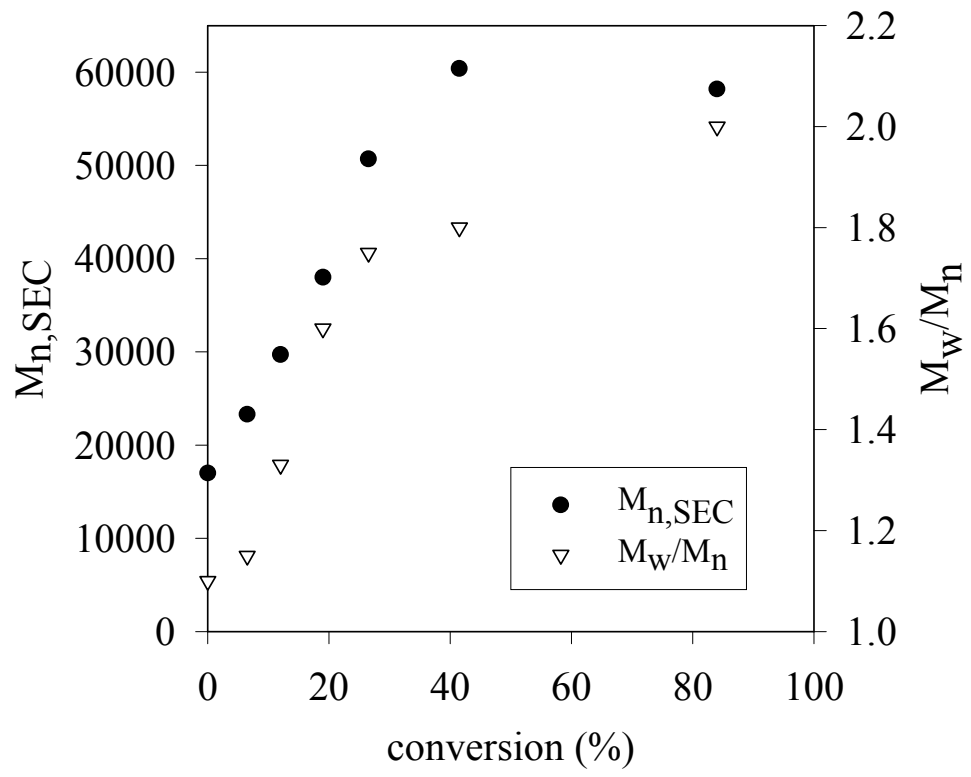

Fig. 10. Resumption of the tBMA polymerization in bulk at $80^{\circ} \mathrm{C}$

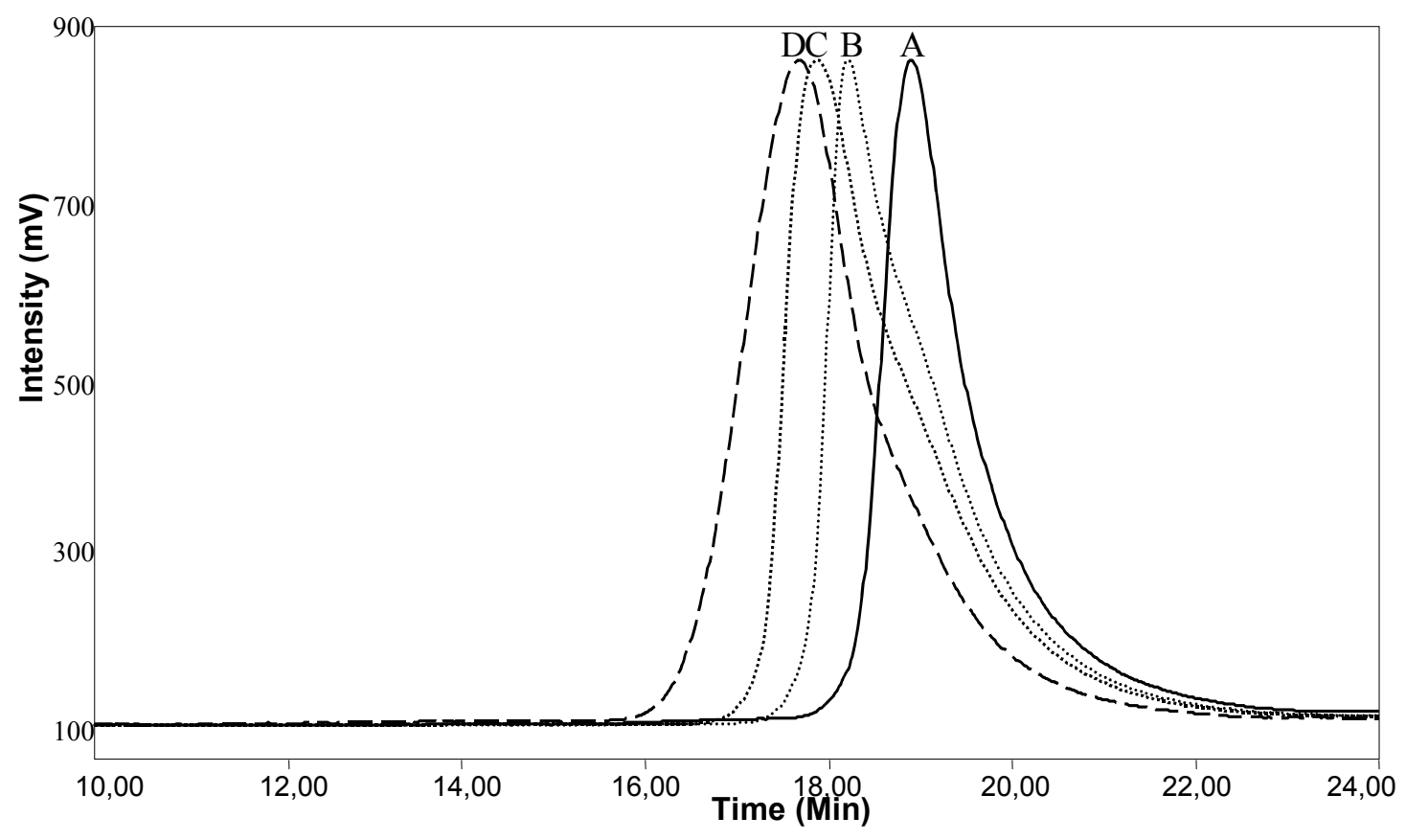

Fig. 11. SEC chromatograms for the tBMA bulk polymerization at $80^{\circ} \mathrm{C}$ (cf. Fig. 10): (A) $M_{n}=23000 ;(B) M_{n}=29700 ;$ (C) $M_{n}=38000 ;$ (D) $M_{n}=60400$ 
- Ascorbic acid is well-known to reduce nitroxyl radicals into corresponding hydroxylamines [14]:<smiles>[R]N([O])O</smiles>

$$
\text { nitroxyl radical hydroxylamine }
$$

Therefore, a too large excess of ascorbic acid might have a detrimental effect on the polymerization control.

All these competitive reactions make the control of the amount of NO, of initiating radicals and nitroxyl radicals in the medium difficult, and thus the optimization of the experimental conditions is hard to achieve.

In addition to these competitive reactions, some specific side reactions have to be pointed out :

- $\beta$-elimination of the terminal methacrylic proton of the active species with formation of an $\omega$-unsaturation [13] is the main termination of the growing polymethacrylate chains in a "classical" NMP process.
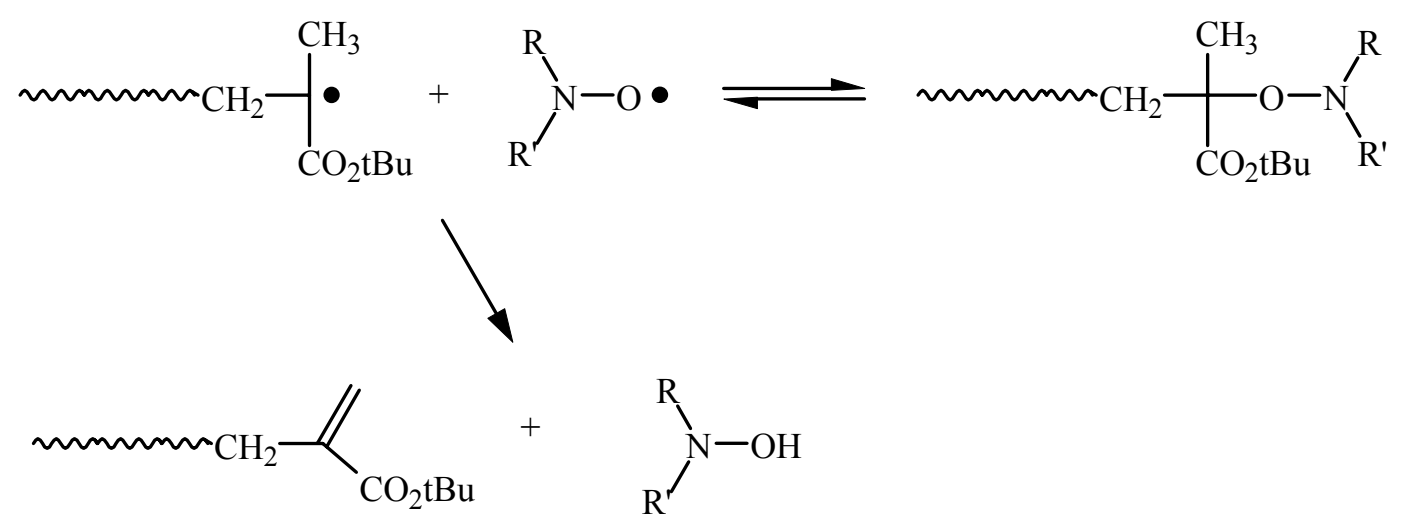

However, in this study, the polymer molecular weight is controlled until complete monomer conversion, which suggests that the extent of chain termination by $\beta-\mathrm{H}$ elimination is restricted.

- Stability of the nitroxyl radical at the temperature used for polymerization is an issue to be addressed. No information is available in the scientific literature on the stability of the nitroxyl formed in the polymerization medium by the sodium nitrite system.

Another crucial issue is the possible reaction of dialkylnitroxyl radicals with nitric oxides: [15]

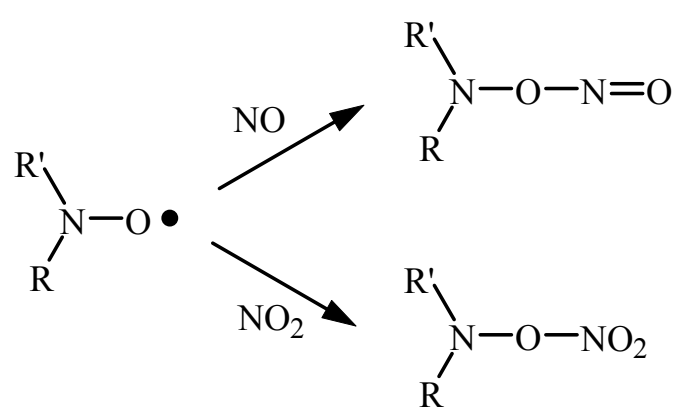


Even tertiary alkyl nitroxyl radicals can react fast at room temperature when the nitric oxide concentration is high. These reactions have to be kept in mind.

In conclusion, a series of competitive and side reactions can occur that should be studied carefully in order to identify the experimental parameters to be tuned, in an effort to optimize the control.

\section{Conclusions}

In spite of some side reactions that occur during the radical polymerization of tBMA, the sodium nitrite/ascorbic acid mixture is a convenient metal-free system for the control of the tBMA polymerization in water. Formation of nitric oxide by reduction of sodium nitrite by ascorbic acid is the key step of the process. Addition of alkyl radicals to $\mathrm{NO}$ forms nitroxyl radicals which reversibly trap the growing chains and provide the polymerization with control.

The ESR observation of nitroxyl radicals when a solution of tBMA oligomers in toluene is heated is the signature of a thermo-labile alkoxyamine (C-ON) at the $\omega$-chain end. There is thus a strong analogy with the NMP mechanism, which may suggest that other monomers, such as styrenes and acrylates, might be polymerized in a controlled manner by this new system, too. Further investigation is in progress in order to optimize the ability of this very simple system to control the radical polymerization of a series of monomers.

Very importantly, NMP is known for a poor control of the alkyl methacrylates polymerization. Therefore, the nitrite system is raising new prospects in this field.

According to the polymerization mechanism, $\mathrm{NO}$ gas could also be used instead of a sodium nitrite/ascorbic acid (or $\mathrm{FeSO}_{4}$ ) mixture to control the free-radical polymerization of vinyl monomers. This alternative will be the topic of a forthcoming paper.

Acknowledgement: The authors are much indebted to the "Services Fédéraux des Affaires Scientifiques, Techniques et Culturelles" for general support to CERM in the frame of the "Pôles d'Attraction Interuniversitaires: PAl 4/11". They are also grateful to Mrs F. Luthers for her skillful assistance.

[1] (a) Moad, G. ; Rizzardo, E. ; Solomon, D.H. Macromolecules 1982, 15, 909. (b) Georges, M.K.; Veregin, R.P.N.; Kazmaier, P.M.; Hamer, G.K.; Macromolecules 1998, 26, 2987. (c) Devonport, W.; Michalak, L.; Malmström, E.; Mate, M.; Kurdi, B.; Hawker, C.J.; Barclay, G.G.; Sinta, R.; Macromolecules 1997, 30, 1929. (d) Jousset, S.; Hammouch, S.O.; Catala, J.-M.; Macromolecules 1997, 30, 6685. (e) Benoit, D.; Grimaldi, S.; Finet, J.-P.; Tordo, P.; Fontanille, M.; Gnanou, Y.; Polym. Prepr. (Am. Chem. Soc., Div. Polym. Chem.) 1997, 38 (1), 729. (f) Fukuda, T.; Terauchi, T.; Goto, A.; Tsuji, Y.; Miyamoto, T.; Shimizu, Y.; Macromolecules 1996, 29, 3050. (g) Benoit, D.; Chaplinski, V.; Braslau, R.; Hawker, C.J.; J. Am. Chem. Soc. 1999, 121, 3904. (h) Benoit, D.; Grimaldi, S.; Robin, S.; Finet, J.P.; Tordo, P.; Gnanou, Y.; J. Am. Chem. Soc. 2000, 122, 5929. (i) Benoit, D.; Harth, E.; Helms, B.; Rees, I.; Vestberg, R.; Rodlert, M.; Hawker, C.J.; ACS Symp. Ser. 2000, 768, 123. (j) Benoit, D.; Harth, E.; Fox, P.; Waymouth, R.M.; Hawker, C.J.; Macromolecules 2000, 33, 363.

[2] (a) Kato, M.; Kamigaito, M.; Sawamoto, M.; Higashimura, T.; Macromolecules 1995, 28, 1721. (b) Ando, T.; Kamigaito, M.; Sawamoto, M.; Macromolecules 1997, 
30, 4507. (c) Wang, J.S.; Matyjaszewski, K.; J. Am. Chem. Soc. 1995, 117, 5614. (d) Matyjaszewski, K.; Coca, S.; Gaynor, S.G.; Wei, M.; Woodworth, B.E.; Macromolecules 1997, 30, 7348. (e) Haddleton, D.M.; Jasieczek, C.B.; Hannon, M.J.; Shooter, A.J.; Macromolecules 1997, 30, 2190. (f) Granel, C.; Dubois, P.; Jerome, R.; Teyssie, P.; Macromolecules 1996, 29, 8576. (g) Moineau, G.; Dubois, P.; Jerome, R.; Senninger, T.; Teyssie, P.; Macromolecules 1998, 31, 545. (h) Moineau, G.; Granel, C.; Dubois, Ph.; Jérôme, R.; Teyssié, Ph.; Macromolecules 1998, 31, 542. (i) Patten, T.E.; Matyjaszewski, K.; Adv. Mater. 1998, 10, 901. (j) Patten, T.E.; Matyjaszewski, K.; Acc. Chem. Res. 1999, 32, 895. (h) Sawamoto, M.; Kamigaito, M.; CHEMTECH 1999, 29, 30.

[3] (a) Chiefari, J.; Chong, Y.K.; Ercole, F.; Krstina, J.; Jeffery, J.; Le, T.P.T.; Mayadunne, R.T.A.: Meijs, G.F.; Moad, C.L.; Moad, G.; Rizzardo, E.; Thang, S.H.; Macromolecules 1998, 31, 5559. (b) Chong, B.Y.K.; Le T.P.T.; Moad, G.; Rizzardo, E.; Thang, S.H.; Macromolecules 1999, 32, 2071. (c) Rizzardo, E.; Chiefari, J.; Mayadunne, R.T.A.; Moad, G.; Thang, S.H.; ACS Symp. Ser. 2000, 768, 278. (d) Rizzardo, E.; Chiefari, J.; Moad, G.; Mayadunne, R.T.A.; Thang, S.H.; Polym. Prep. 1999, 40, 342. (e) Destarac, M.; Charmot, D.; Franck, X.; Zard, S.Z.; Macromol. Rapid Commun. 2000, 21, 1035.

[4] (a) Bon, S.A.F.; Bosveld, M.; Klumperman, B.; German, A.L.; Macromolecules 1997, 30, 3240. (b) Gaynor, S.G.; Qiu, J.; Matyjaszewski, K.; Macromolecules 1998, 31, 5951. (c) Nishikawa, T.; Kamigaito, M.; Sawamoto, M.; Macromolecules 1999, 32, 2204. (d) Lansalot, M.; Farcet, C.; Charleux, B.; Vairon, J.P.; Pirri, R.; Tordo, P. ; ACS Symp. Ser. 2000, 768, 138. (e) Farcet, C.; Lansalot, M.; Charleux, B.; Pirri, R.; Vairon, J.P. ; Macromolecules 2000, 33, 8559.

[5] (a) Detrembleur, C.; Ph.D. thesis: Developments of new regulators for controlled radical polymerization, University of Liege 2001. (b) Detrembleur, C.; Teyssie, Ph.; Jerome, R.; Macromolecules, submitted.

[6] Bortel, E.; Kochanowski, A.; Kudla, S.; Witek, E.; J. Macromol. Sci. - Pure Appl. Chem. 1998, A35(2), 401.

[7] (a) Bunton, C.A.; Dahn, H.; Loewe, L.; Nature 1959, 183, 163. (b) Woolum, J.C.; Tiezzi, E.; Commoner, B.; Biochim. Biophys. Acta 1968, 160, 311.

[8] Patnaik, S.; Ray, A.K.; Baral, N.; Nayak, P.L.; J. Macromol. Sci. - Chem. 1979, A13(6), 797.

[9] (a) Gingras, B.; Waters, W.A.; Chem. Ind. 1953, 615. (b) Gingras, B.A.; Waters, W.A.; J. Chem. Soc. 1954, II, 1920. (c) Chilton, H.T.J.; Gowenlock, B.G.; J. Chem. Soc. 1954, 3174. (d) Christie, M.I.; Frost, J.S. ; Trans. Faraday Soc. 1965, 61, 468. (e) Rockenbauer, A.; Gyor, M.; Tudos, F.; Tetrahedron Lett. 1986, 27, 3425.

[10] (a) Sato, T.; Otsu, T.; Makromol. Chem. 1977, 178, 1941 and 1951. (b) Chalfont, G.R.; Perkins, M.J.; J. Am. Chem. Soc. 1967, 89, 3054. (c) Lagercrantz, C.; J. Phys. Chem. 1971, 75, 3467. (d) Janzen, E.G.; Accounts Chem. Res. 1971, 4, 31. (e) Evans, C. A.; Aldrichimica Acta 1979, 12, 23. (f) Hoffman, A.K.; French Patent 1,357,477 (1964); Chem. Abstr. 1964, 61, 8191. US Patent 3,253,015 (1966); Chem. Abstr. 1966, 65, 15225. (g) S.F. Nelsen; in "Free Radicals", J.K. Kochi, WileyInterscience, New York, VII, 1973, 545 - 550. (h) Jonkman, L.; Muller, H.; Kommandeur, J.; J. Am. Chem. Soc. 1971, 93, 5833. (i) Rockenbauer, A.; Gyor, M.; Tudos, F.; Tetrahedron Lett. 1986, 27, 3425. 
[11] Grishin, D.F.; Semyonycheva, L.L.; Kolyakina, E.V.; Mendeleev Commun. 1999, 250.

[12] Knowles, P.F.; Marsh, D.; Rattle, H.W.E.; "Magnetic Resonance of Biomolecules", John Wiley \& Sons, 1976.

[13] (a) Gridnev, A.A.; Macromolecules 1997, 30, 7651. (b) Nishikawa, T.; Ando, T.; Kamigaito, M.; Sawamoto, M.; Macromolecules 1997, 30, 2244. (c) Moad, G.; Anderson, A.G.; Ercole, F.; Johnson, C.H.J.; Krstina, J.; Moad, C.L.; Rizzardo, E.; Spurling, T.H.; Thang, S.H.; ACS Symp. Ser. 1998, 685, 332.

[14] (a) Paleos, C. S.; Dais, P.; J. Chem. Soc., Chem. Commun. 1977, 10, 345. (b) Kveder, M.; Pifat, G.; Slavko, P.; Schara, M.; Ramos, P.; Esterbauer, H.; Chem. Phys. Lipids 1997, 85(1), 1. (c) Mehlhorn, R. J.; J. Biol. Chem. 1991, 266(5), 2724.

[15] (a) Forrester, A.R.; Hay, J.M.; Thomson, R.H.; "Organic Chemistry of Stable Free Radicals", Academic Press, London and New York 1968, 221 - 224 (see refs. herein). (b) Gyor, M.; Rockenbauer, A.; Tudos, F.; Tetrahedron Lett. 1986, 27, 3759. 